\title{
Definitions, variants, and causes of nonadherence with medication: a challenge for tailored interventions
}

\author{
Jacqueline G Hugtenburg' \\ Lonneke Timmers' \\ Petra JM Elders ${ }^{2}$ \\ Marcia Vervloet ${ }^{3}$ \\ Liset van Dijk ${ }^{3}$
}

'EMGO+ Institute and Department of Clinical Pharmacology and Pharmacy, VU University Medical Center, Amsterdam, ${ }^{2} \mathrm{ANH}-\mathrm{VUmc}$, VU University Medical Center, Amsterdam, ${ }^{3} \mathrm{NIVEL}$, Netherlands Institute for Health Services Research, Utrecht, The Netherlands
Correspondence: Jacqueline G Hugtenburg

Department of Clinical Pharmacology and Pharmacy, VU University Medical Center, De Boelelaan II I7, I08I HV Amsterdam, The Netherlands

Tel +3I 204443524

Fax +3I 204443525

Email jg.hugtenburg@vumc.nl
This article was published in the following Dove Press journal:

Patient Preference and Adherence

9 July 2013

Number of times this article has been viewed

Background: Nonadherence with medication is a complex and multidimensional health care problem. The causes may be related to the patient, treatment, and/or health care provider. As a consequence, substantial numbers of patients do not benefit optimally from pharmacotherapy, resulting in increased morbidity and mortality as well as increased societal costs. Several interventions may contribute to improved adherence. However, most interventions have only a modest effect. Thus, despite the many efforts made, there has been little progress made as yet in tackling the problem of nonadherence.

Methods: This paper summarizes the definitions and taxonomy of adherence with medication, as well as types and causes of nonadherence. In addition, interventions aimed at improvement of adherence are discussed.

Conclusion: There is not just one solution for the nonadherence problem that fits all patients. Most interventions to improve adherence are aimed at all patients regardless of whether they are adherent or not. Recently, a number of tailored interventions have been described in the literature. Modern techniques are useful. Electronic pill boxes combined with Short Message Service reminders are specifically designed to improve unintentional adherence and have resulted in an increase in refill adherence in diabetic patients with suboptimal adherence. Tailored Internet interventions are a possibility for influencing patient drug-taking behavior and show promising results. Tailored counseling interventions targeted at the underlying causes of nonadherence seem an attractive method for supporting patients with their use of drugs. However, despite the plausible theoretical framework, data on long-term health effects of the various interventions are not available. To improve adherence effectively, there is a need for a tailored approach based on the type and cause of nonadherence and the specific needs of the patient.

Keywords: adherence, compliance, concordance, tailored intervention

\section{Introduction}

Nonadherence with medication is a complex and multidimensional health care problem. Adherence is defined as the extent to which patients are able to follow the recommendations for prescribed treatments. Patients may be nonadherent during different stages of their treatment. ${ }^{1}$ They may decide not to fill their prescriptions in the pharmacy and not start their treatment at all. Patients may use more or less than the prescribed treatment or use their medication at the wrong time. They may also discontinue treatment prematurely. Patients' reasons for deviating from the (agreed) treatment plan are diverse and may be intentional or unintentional. ${ }^{2-4}$ The causes of nonadherence may be related to the patient, treatment, and/or health care provider. For example, patients may not believe the treatment is necessary, ${ }^{5}$ complex treatment 
plans may increase the risk of nonadherence, ${ }^{6,7}$ and there may be insufficient communication between patient and provider. ${ }^{8,9}$

A meta-analysis of 569 studies of medication adherence revealed an average nonadherence rate of $25 \% .{ }^{10}$ Adherence is highest in patients with human deficiency virus infection, arthritis, gastrointestinal disorders, or cancer, and lowest in patients with pulmonary disease, diabetes mellitus, or sleep disorders. It is generally thought that the gravity of the disease motivates patients to take their medication exactly as prescribed. ${ }^{11}$

Cancer patients appear to have adherence rates similar to those of patients with other diseases. ${ }^{12}$ Due to the often short life expectancy, most oral anticancer agents are used for a relatively short period. However, medication in chronic malignant diseases like chronic myeloid leukemia is used for several years. Studies concerning adherence with medication for chronic myeloid leukemia highlight serious problems, with a quarter to one third of patients being nonadherent, ${ }^{13-15}$ which is accompanied by a reduced molecular response. Adjuvant hormonal pharmacotherapy for patients with breast cancer is another example of long-term treatment of a serious disease with adherence problems. ${ }^{16,17}$

As a consequence of nonadherence, substantial numbers of patients do not benefit optimally from medication, resulting in increased morbidity and mortality as well as increased societal costs. ${ }^{18-23}$ In 2006, Simpson et al reported a meta-analysis of observational studies and control arms of randomized clinical trials on the association between nonadherence and mortality. ${ }^{24}$ Eight studies included patients with a recent myocardial infarction, seven studies reported on patients with human deficiency virus infection, and the remaining studies included predominantly patients with cardiovascular diseases other than myocardial infarction. The results, based on data from observational studies, showed that patients who were adherent with treatment survived significantly longer, ie, 1462 of 31,439 (4.7\%) adherent patients died, as compared with 1317 of 15,408 (8.5\%) patients with suboptimal adherence (odds ratio [OR] 0.56, $95 \%$ confidence interval $[\mathrm{CI}] 0.50-0.63)$. In control groups from randomized trials, adherence was also associated with a significantly lower mortality (OR $0.56,95 \%$ CI $0.43-0.74$ ). The authors suggested that adherence is associated with healthy behavior in general, known as the "healthy adherer effect". The elderly are a patient group that is vulnerable to negative health outcomes due to lack of adherence. Because older patients often use a variety of drugs for a number of chronic diseases, the consequences of nonadherence may be more serious, but nonadherence may be less easily detected and resolved than in younger age groups..$^{25}$

Several interventions may contribute to improved adherence, thereby resulting in health gain and cost reduction. Complications may be avoided, patients do not need to switch to more expensive treatments, and less health care may be utilized. In addition, because adherent patients may be healthier, their work productivity may increase. ${ }^{26}$ However, several reviews summarizing the effectiveness of interventions promoting adherence revealed that only half of the interventions were associated with a significant increase in adherence and even fewer reported an improvement in treatment outcomes. ${ }^{10,27-31}$ Even the most effective interventions had only modest effects.

Thus, despite many efforts, little progress has been made in tackling the nonadherence problem. Moreover, interventions may also have been applied to patients for whom they are not suited. Interventions are often aimed at all patients, regardless of whether they are adherent or not. In addition to that, it is inefficient and costly to include patients who have no or only minor problems in being adherent with their treatment, and the indiscriminate use of interventions dilutes their effect. Although it may be difficult to identify nonadherent patients, an effort should be made, since these patients would benefit most from adherence-enhancing interventions. ${ }^{32}$ Further, few interventions have been tailored to the specific needs of the individual patient. It seems that there is not just one solution for the nonadherence problem that fits all patients, and there is a need for a tailored approach based on the type and cause of nonadherence. ${ }^{32,33}$ This paper summarizes the definitions and taxonomy of adherence, as well as types and causes of nonadherence. In addition, interventions aimed at improvement of medication adherence are discussed. We focus in particular on tailored interventions.

\section{Definitions of adherence}

"Compliance", "adherence", "persistence", and "concordance" are terms related to the suboptimal taking of medicine by patients. Although often used interchangeably, they impose different views on the relationship between the patient and the health care professional, collection of medicines from the pharmacy, and their appropriate intake. Compliance can be defined as the extent to which the patient follows the recommendations of the prescriber. In this classic situation, the prescriber tells the patient how to use the medication. ${ }^{34}$ Adherence is the extent to which medication intake behavior corresponds with the recommendations of the health care provider. ${ }^{33,35}$ Patient compliance and medication adherence 
have been previously defined as synonymous. ${ }^{36}$ However, in recent years, compliance has been viewed by many as having the negative connotation that patients are subservient to prescribers, and the term "adherence with medication" is now the preferred terminology. ${ }^{1}$ In contrast, concordance refers to an agreement between the prescriber and patient on the purpose and use of the medication. However, this term is increasingly used to address the appropriateness of medication intake behavior. ${ }^{37}$ Concordance is sometimes incorrectly used as a synonym for "compliance" or "adherence". Persistence is the length of time between the first and last dose, being applicable in the event that a patient discontinues treatment. ${ }^{38}$ Whereas persistence refers to how long patients stay on treatment, adherence refers to how well they implement the prescribed regimen. Patients often discontinue relatively soon after starting treatment. For antidepressants, it was shown that patients who have been prescribed these drugs did not start their medicines at all in $4.2 \%$ of cases and that $23.7 \%$ filled only a single prescription. ${ }^{39}$

\section{Taxonomy of adherence}

Vrijens et al have recently summarized the history and literature on the taxonomy of adherence. ${ }^{1}$ Around $400 \mathrm{BC}$, Hippocrates was the first to note that some patients did not take their medicines as prescribed, and later complained that their treatment did not help. For the first time in modern medicine, Robert Koch in 1882 commented that noncompliant patients with tuberculosis were "vicious consumptives, careless and/or irresponsible." At the end of the seventies, the groundwork for current adherence research was performed. At that time, only the term compliance was used and studies were focused on the effect of noncompliance on the outcome of treatment in clinical trials. The perspective of the patient was not yet recognized. Later studies addressed the way prescriptions were generated, the influence of patients on this process, and medication intake in daily life. Parallel to this development, the term compliance was increasingly replaced by adherence. Gradually, the idea of cooperation and agreement between prescriber and patient was incorporated into adherence, while compliance referred to the following of instructions given by prescribers. These changes finally led to the proposal of using the term "concordance" by the joint working group convened by the Royal Pharmaceutical Society of the UK. ${ }^{40}$ Although prescriber and patient may have different views, it was widely recognized that appropriate medication-taking behavior is conditional on agreement between patients and prescribers.
The willingness of the patient to use the drug plays an important role in adherence. It should be taken into account that adherence, compliance, and persistence, but not concordance, are terms that may be used to describe the level of inappropriate drug use.

\section{Intentional versus unintentional nonadherence}

Of great importance for the development of tailored solutions to nonadherence is awareness of intentional and unintentional adherence. Intentional nonadherence can be considered as a process in which the patient actively decides not to use treatment or follow treatment recommendations. This usually reflects a rational decision-making process in which the patient weighs the pros and cons of the treatment. ${ }^{2}$ Patient beliefs and the level of cognition are important factors in this process. ${ }^{2-5}$ This may be difficult for patients. For example, on the basis of the patient information leaflet, patients may become skeptical about their medication because of side effects and other disadvantages, such as drug dependency, masking of other diseases, or reduced long-term efficacy. In addition, using certain medication can be stigmatizing or remind patients that they are ill. ${ }^{33}$ These factors may contribute to a lack of motivation to use the necessary medication. Communication with patients may provide the health professional with the insight into these subjective patient norms. Patient counseling may improve adherence after exploring these norms.

Unintentional nonadherence refers to unplanned behavior and is less strongly associated with beliefs and the level of cognition than intentional nonadherence. ${ }^{2-5}$ Unintentional adherence may be the result of forgetfulness and not knowing exactly how to use medicines. ${ }^{2-4}$ As such, it is a passive process that is specifically associated with the complexity of a medication regimen and the patient's memory (either forgetting to take the medication at the prescribed time or poor recall of instructions). ${ }^{3,41}$ Interventions addressing this type of nonadherence may need to focus on simplifying the regimen, reminding patients to take their medication, and supporting patients in making the intake of medication part of their daily routine.

Use of multiple medications (polypharmacy) is associated with an increased risk of complex dosing schemes. The need to manage potential drug-drug interactions may also result in complex dosing schemes. For example, the need to take tetracyclines or bisphosphonates separately from calcium, aluminum, magnesium, or iron salts. Bisphosphonates and thyroid hormones should be taken at least half an hour 
before breakfast. On the other hand, some drugs should not be taken on an empty stomach, but with a meal, implying a complicated schedule for the patient to follow.

Predictors of nonadherence may contribute to the detection and type of nonadherence. Gender and socioeconomic status do not appear to influence nonadherence. On the other hand, several studies have shown reduced adherence in ethnic minorities. ${ }^{39,42}$ Factors that may predict nonadherence include forgetfulness, illiteracy, inability to understand the purpose of treatment, not perceiving the treatment as necessary, a lack of trust in the treatment, and a lack of knowledge about the effects of treatment. In addition, psychiatric problems, including depression, cognitive limitations, missing visits, and a poor relationship with the health care provider have also been found to contribute to nonadherence. Some of these factors are associated with intentional nonadherence, while others are more likely to be correlated with unintentional nonadherence. ${ }^{33}$

\section{Interventions to improve adherence}

Several interventions have been reported in the literature to improve nonadherence. A number of these interventions are discussed here.

\section{Interventions for unintentional nonadherence}

Interventions directed towards unintentional nonadherence include simplification of dosing regimens, reminders, improved communication between patient and physician, and introduction or improvement of patient counseling. A metaanalysis of 76 studies showed that adherence decreased with the frequency of the regimen, ie, $72 \%$ of patients on a oncedaily regimen adhered with treatment, $69 \%$ with a twice-daily regimen, $65 \%$ with a three times daily regimen, and 51\% with a four times daily regimen. ${ }^{27}$ Adherence can be improved by using specific forms of drug packaging. In this respect, weekly boxes and single-dose blisters with an indication of day and time are commonly used. Zedler et al studied the effects of calendar packaging in ten trials, including a total of 1045 patients. In seven studies, calendar packaging was used as a single adherence intervention. Six of these studies reported positive effects on adherence..$^{43}$

\section{Modern technologies}

\section{and unintentional nonadherence}

Attempts to increase adherence are increasingly using modern technologies. So far, most of them have been directed towards improving unintentional nonadherence. At present, the Internet and mobile phone are often used in interventions to increase adherence. With the number of mobile phone connections now exceeding six billion worldwide, ${ }^{44}$ reminding patients to take their medication by Short Message Service (SMS) is increasingly being used. SMS allows for instantaneous delivery of short text messages to individuals at any time, place, and setting. As such, SMS reminding is a simple method with low intrusiveness and relatively low cost. ${ }^{45}$

A systematic review of 13 studies by Vervloet et al showed positive effects on adherence using electronic reminder systems, including SMS. ${ }^{31}$ Four studies investigated the effects of SMS reminders, seven concerned audiovisual reminder systems, and two investigated electronic text messages. Evidence was found for the short-term effectiveness of electronic reminders, with significant improvements in adherence found in all but two studies following patients for periods less than six months. Only three studies followed patients for a period longer than six months, one of which found significant effects on adherence as a result of SMS reminders. As such, the longterm effectiveness of electronic reminders remains unknown. All studies included in this review investigated the effect of reminders at given time points, regardless of whether the medication was taken or not. Real time medication monitoring was recently introduced. Similar to the well-known Medication Event Monitoring System ${ }^{\circledR}$, real time medication monitoring is an electronic medicine box which registers the date and time the box was opened (Simpill; Evalan, Amsterdam, The Netherlands). In this manner, a detailed record of drug intake can be generated. Using a central server, drug taking may be followed in real time, offering the opportunity to send an SMS in the event that the patient does not open the box within a certain time frame. A study including patients with type 2 diabetes mellitus and suboptimal refill adherence showed that real time medication monitoring combined with SMS reminders resulted in more regular drug intake and an improved drug refill rate. ${ }^{46}$

\section{Behavioral interventions for intentional nonadherence}

Interventions aimed at increasing knowledge about the disease and its treatment and addressing patient concerns or fears about potential side effects may provide solutions for intentional nonadherence. Motivational interviewing is a method used to explore the reasons for barriers to medication intake. It helps patients to explore their ambivalence and can motivate them to resolve their problems as well as prevent future intake problems. It is a patient-centered method of communication and is intended to stimulate 
behavioral change. ${ }^{47}$ With regard to adherence, patients are supported to clarify potential barriers to medication use and to formulate their own solutions. As such, motivational interviewing is a balance between directing, advising, and supporting the patient on the one hand and encouraging the patient to find possible solutions on the other. A systematic review of 72 studies reported that motivational interviewing outperformed traditional advice in $80 \%$ of cases. ${ }^{48}$ However, it is important to avoid provider-centered communication because this affects patient participation in a negative manner. Interrupting the patient is an example of providercentered communication. Albeit sometimes crucial in order to keep control, interrupting may also discourage the patient from active participation in the consultation. Interruptions must be kept to a minimum. Dialog between patient and provider is of utmost importance, in particular when discussing adherence. Health care providers should never assume that a patient is adherent. Questioning the patient about habits of medication use is also recommended, and the interviewing technique can be improved in clinical practice. In a study by Van Dulmen and Van Bijnen, general practitioners were shown videotapes of their own consultations. ${ }^{9}$ Afterwards, they were asked why they did not pose certain questions or why some of the patients' questions were ignored. General practitioners often mentioned lack of time as the reason for this, but there was also an element of assumption that the patient was adherent.

\section{Effects of tailored interventions on health outcome}

Haynes et al reviewed the effects of interventions aimed at improving adherence. ${ }^{27}$ For short-term treatments, four of 10 interventions reported in nine randomized controlled trials showed an effect on both adherence and at least one clinical outcome, whereas intervention in one randomized controlled trial resulted in significant improvement in patient adherence but did not improve the clinical outcome. With regard to long-term treatment, 36 of 81 interventions reported in 69 randomized controlled trials were associated with improved adherence, but only 25 interventions led to improvement of least one treatment outcome. Nearly all interventions that were effective in long-term care were complex. They included combinations of more convenient care, information, reminders, self-monitoring, reinforcement, counseling, family therapy, psychological therapy, crisis intervention, manual telephone follow-up, and supportive care. Although the studies were too heterogeneous to assess their effects quantitatively, the authors of this Cochrane review concluded that even the most effective interventions did not lead to substantial improvement in adherence or treatment outcome.

A likely reason for these poor results may be that most of the interventions were complex. This may have hampered their implementation in daily practice because feasibility has been shown to be an important factor contributing to the success of an intervention.

Another reason for the poor results may be that most of the interventions used were not tailored to the needs of the individual patient. Usual interventions are aimed at all patients regardless of whether they are adherent or not. Not only is it inefficient and costly to include patients who have no or minor adherence problems but there is also a dilution of the effect of the intervention because these patients have no or little room for improvement. ${ }^{31}$ In 2003, the World Health Organization stressed the need to tailor interventions to the needs of the patient because nonadherence is a multidimensional problem..$^{33}$ Therefore, it is important to get to know the main drivers of nonadherence. DiMatteo et $\mathrm{al}^{49}$ recently presented a simple clinical approach based on recognition of the following reasons for nonadherence: patients do not understand what they have to do; patients are not motivated; and patients have no strategy for following treatment recommendations. In the event that patients do not understand what they have to do, it is important to inform them about what to do in such a way that they understand and recall the information. Recallpromoting strategies that can be used include repeating information and offering supporting materials. When patients are not motivated, they experience perceptual barriers to taking their medication because they doubt the need for medication or are concerned about its negative effects. ${ }^{2}$ Communication strategies aiming at reducing such perceptual barriers include motivational interviewing techniques but also showing understanding by using affective communication strategies. In the event that patients have no strategy to follow, a strategy should be developed in such way that it fits the patient. For example, if the patient has difficulty remembering to take the medication, a reminder system may be helpful.

In order to be able to tailor an intervention to the needs of the patient, it is important to signal nonadherence, to detect the reason for nonadherence, and to discuss potential solutions with the patient. So far, not many studies in the field of adherence have followed this approach. One example is a study by Herborg et $\mathrm{al}^{50}$ in which an interventional toolbox was developed, enabling pharmacy staff and general practitioners to tailor a counseling program for individual patients. These tools were divided in five groups: evaluating medicines 
and drug-related problems (eg, checking for interactions, dose regimens, and adverse reactions); patient counseling and coaching (eg, motivation interview techniques); patient education and information (eg, written, video, and Internetbased information sources); reminder technologies (eg, SMS reminders, telephone reminders); and communication tools. They argue that in order to use this toolbox in a rational way, "it is important not to return to simplistic models, but to have a professional routine to find the right tools for the individual patient". As such, strong patient-provider communication is the basis for every tailored approach.

This was also acknowledged by Adhien et al, who developed a tailored, modular pharmacy-based intervention for community pharmacists to support nonadherent diabetic patients with their medication intake. ${ }^{51}$ The interventions for individual patients are tailored to the underlying causes of nonadherence. To gain insight into the causes, a structured patient interview is performed by a pharmacy technician. Using an intervention guide, the pharmacist is guided to one of the following interventions: tackling the motivation of patients to take their medicines by means of motivational interviewing; tackling the problem of "the current treatment does not work" in consultation with the general practitioner, so that another dose or drug is selected, and/or counseling the patient on the effects of treatment; tackling the problem of "side effects" in consultation with the general practitioner, a lower dose, another drug, and/or counseling the patient; intervention to facilitate swallowing the drug, such as a tablet in an empty capsule or a tablet ground into powder; and offering a tool to help the patient "remember" to take their medication in a timely manner. The intervention appeared feasible, but its effectiveness has yet to be demonstrated in a randomized controlled trial. ${ }^{51}$

The Internet can also be used to promote adherence. In a review of 13 studies, Linn et al concluded that e-health interventions may be effective in promoting adherence. ${ }^{30}$ Tailored Internet interventions differ in the level of sophistication used for message delivery. ${ }^{52}$ Some interventions involve only a form of online assessment (low sophistication), whereas others use online assessments, tailored feedback (eg, information specifically addressing the information needs of a particular patient), and content matching (moderate sophistication).

Finally, there are interventions that provide instant feedback and a complex tailored health program with several tools and activities that may enable patients to achieve their health goals (high sophistication). All interventions described in the review by Linn et al were moderately or highly sophisticated. The authors concluded that: "This review shows promising results on the effectiveness of Internet interventions to enhance patients' adherence to prescribed long-term medications. Although there is evidence according to the data synthesis, the results must be interpreted with caution due to low-quality adherence measurements."

\section{Conclusion}

Nonadherence with medication is a complex and multidimensional health care problem. Several reviews summarizing the effectiveness of adherence-promoting interventions show that only half of these interventions resulted in increased adherence with medication and even fewer reported improvement in treatment outcomes. Even the most effective interventions had only a modest effect.

The interventions were aimed at all patients regardless of whether they were adherent or not, and few were tailored to the specific needs of the patient. It is clear that there is not just one solution to the problem of nonadherence that fits all patients. Therefore, there is a pressing need for a tailored approach based on the type and cause of nonadherence. A number of tailored interventions have been described in the recent literature. Real time medication monitoring combined with SMS reminders have resulted in a markedly increased refill adherence in diabetic patients with suboptimal adherence. These types of interventions are specifically designed to improve unintentional adherence. Tailored Internet interventions are another strategy for influencing patient drug-taking behavior and have shown promising results. A tailored pharmacist-based intervention targeted to the underlying causes of nonadherence seems to be an attractive method for supporting patients in their use of drugs. However, despite the plausible theoretical frameworks for interventions to improve adherence, data on long-term health outcomes are not available.

\section{Disclosure}

The authors report no conflicts of interest in this work.

\section{References}

1. Vrijens B, De Geest S, Hughes DA, et al. A new taxonomy for describing and defining adherence to medications. Br J Clin Pharmacol. 2012;73(5):691-705.

2. Wroe AL. Intentional and unintentional nonadherence: a study of decision making. J Behav Med. 2002;25(4):355-372.

3. Lehane E, McCarthy G. Intentional and unintentional medication non-adherence: a comprehensive framework for clinical research and practice? A discussion paper. Int J Nurs Stud. 2007;44(8):1468-1477. 
4. Lowry KP, Dudley TK, Oddone EZ, Bosworth HB. Intentional and unintentional nonadherence to antihypertensive medication. Ann Pharmacother. 2005;39(7-8):1198-1203.

5. Clifford S, Barber N, Horne R. Understanding different beliefs held by adherers, unintentional nonadherers, and intentional nonadherers: application of the Necessity-Concerns Framework. J Psychosom Res. 2008;64(1):41-46.

6. Bangalore S, Kamalakkannan G, Parkar S, Messerli FH. Fixed-dose combinations improve medication compliance: a meta-analysis. $\mathrm{Am} \mathrm{J}$ Med. 2007;120(8):713-719.

7. Claxton AJ, Cramer J, Pierce C. A systematic review of the associations between dose regimens and medication compliance. Clin Ther. 2001; 23(8):1296-1310.

8. Linn AJ, van Weert JC, Smit EG, Schouten BC, Van Bodegraven A, Van Dijk L. Words that make pills easier to swallow: a communication typology to address practical and perceptual barriers to medication intake behavior. Patient Prefer Adherence. 2012;6:871-885.

9. van Dulmen S, van Bijnen E. What makes them (not) talk about proper medication use with their patients? An analysis of the determinants of GP communication using reflective practice. Int J Pers Cent Med. 2011;1: $27-34$.

10. van Dulmen S, Sluijs E, van Dijk L, de Ridder D, Heerdink R, Bensing J. Patient adherence to medical treatment: a review of reviews. BMC Health Serv Res. 2007;7:55.

11. Nilsson JLG, Andersson K, Bergkvist A, Bjorkman I, Brismar A, Moen J. Refill adherence to repeat prescriptions of cancer drugs to ambulatory patients. Eur J Cancer Care (Engl). 2006;15(3):235-237.

12. Ruddy K, Mayer E, Partridge A. Patient adherence and persistence with oral anticancer treatment. CA Cancer J Clin. 2009;59(1):56-66.

13. Noens L, van Lierde MA, De Bock R, et al. Prevalence, determinants, and outcomes of nonadherence to imatinib therapy in patients with chronic myeloid leukemia: the ADAGIO study. Blood. 2009;113(22): 5401-5411.

14. Marin D, Bazeos A, Mahon F, et al. Adherence is the critical factor for achieving molecular responses in patients with chronic myeloid leukemia who achieve complete cytogenetic responses on imatinib. J Clin Oncol. 2010;28(14):2381-2388.

15. Jabbour EJ, Kantarjian H, Eliasson L, Cornelison AM, Marin D. Patient adherence to tyrosine kinase inhibitor therapy in chronic myeloid leukemia. Am J Hematol. 2012;87(7):687-691.

16. Partridge $\mathrm{AH}$, Archer L, Kornblith AB, et al. Adherence and persistence with oral adjuvant chemotherapy in older women with early-stage breast cancer in CALGB 49907: adherence companion study 60104. J Clin Oncol. 2010;28(14):2418-2422.

17. Ruddy KJ, Partridge AH. Adherence with adjuvant hormonal therapy for breast cancer. Ann Oncol. 2009;20(3):401-402.

18. Sokol MC, McGuigan KA, Verbrugge RR, Epstein RS. Impact of medication adherence on hospitalization risk and healthcare cost. Med Care. 2005;43(6):521-530.

19. Roebuck MC, Liberman JN, Gemmill-Toyama M, Brennan TA. Medication adherence leads to lower health care use and costs despite increased drug spending. Health Aff (Millwood). 2011;30(1):91-99.

20. Dragomir A, Cote R, Roy L, et al. Impact of adherence to antihypertensive agents on clinical outcomes and hospitalization costs. Med Care. 2010;48(5):418-425.

21. Faught RE, Weiner JR, Guerin A, Cunnington MC, Duh MS. Impact of nonadherence to antiepileptic drugs on health care utilization and costs: findings from the RANSOM study. Epilepsia. 2009;50(3):501-519.

22. Esposito D, Bagchi AD, Verdier JM, Bencio DS, Kim MS. Medicaid beneficiaries with congestive heart failure: association of medication adherence with healthcare use and costs. Am J Manag Care. 2009;15(7): 437-445.

23. Halpern R, Becker L, Iqbal SU, Kazis LE, Macarios D, Badamgarav E. The association of adherence to osteoporosis therapies with fracture, all-cause medical costs, and all-cause hospitalizations: a retrospective claims analysis of female health plan enrollees with osteoporosis J Manag Care Pharm. 2011;17(1):25-39.
24. Simpson SH, Eurich DT, Majumdar SR, et al. A meta-analysis of the association between adherence to drug therapy and mortality. BMJ. 2006;333(7557): 15 .

25. Steinman MA, Handler SM, Gurwitz JH, Schiff GD, Covinsky KE. Beyond the prescription: medication monitoring and adverse drug events in older adults. J Am Geriatr Soc. 2011;59(8):1513-1520.

26. Booz\&co. KNMP - The potential for pharmaceutical quality services. Available from: http://www.knmp.nl/downloads/nieuws/booz-co-thepotential-for-pharmaceutical-quality-services. Accessed April 11, 2013.

27. Haynes RB, Ackloo E, Sahota N, McDonald HP, Yao X. Interventions for enhancing medication adherence. Cochrane Database Syst Rev. 2008;2:CD000011.

28. McDonald HP, Garg AX, Haynes RB. Interventions to enhance patient adherence to medication prescriptions: scientific review. JAMA. 2002;288(22):2868-2679.

29. Kripalani S, Yao X, Haynes RB. Interventions to enhance medication adherence in chronic medical conditions: a systematic review. Arch Intern Med. 2007;167(6):540-550.

30. Linn AJ, Vervloet M, Van Dijk L, Smit EG, van Weert JC. Effects of eHealth interventions on treatment adherence: a systematic review of all literature. J Med Internet Res. 2011;13(4):103.

31. Vervloet M, Linn AJ, van Weert JC, de Bakker DH, Bouvy ML, van DL. The effectiveness of interventions using electronic reminders to improve adherence to chronic medication: a systematic review of the literature. J Am Med Inform Assoc. 2012;19(5): 696-704.

32. van Dulmen S, Sluijs E, van Dijk L, et al. Furthering patient adherence: a position paper of the international expert forum on patient adherence based on an internet forum discussion. BMC Health Serv Res. 2008;8:47.

33. Sabaté E. Adherence to Long-Term Therapies. Evidence for Action. Geneva, Switzerland: World Health Organization; 2003.

34. Haynes RB, Taylor DW, Sackett DL. Compliance in Health Care, 1st ed. Baltimore, MD: John Hopkins University Press; 1979.

35. ABC Project Team. Ascertaining barriers for compliance: policies for safe, effective and cost-effective use of medicines in Europe. Final report of the $\mathrm{ABC}$ project. Available from: http://abcproject.eu/img/ ABC\%20Final.pdf. Accessed April 11, 2013.

36. Cramer JA, Roy A, Burrell A, et al. Medication compliance and persistence: terminology and definitions. Value Health. 2008;11(1): 44-47.

37. Bell JS, Airaksinen MS, Lyles A, Chen TF, Aslani P. Concordance is not synonymous with compliance or adherence. Br J Clin Pharmacol. 2007;64(5):710-711.

38. Urquhart J, Vrijens B. New findings about patient adhernce to prescribed drug dosing regimens: an introduction to pharmionics. Eur $J$ Hosp Pharm Sci. 2005;11:103-106.

39. van Geffen EC, Gardarsdottir H, van Hulten R, van Dijk L, Egberts AC, Heerdink ER. Initiation of antidepressant therapy: do patients follow the GP's prescription? Br J Gen Pract. 2009;59(559):81-87.

40. Royal Pharmaceutical Society of Great Britain and Merck Sharp and Dohme. Partnership in Medicine Taking: A Consultative Document. London, UK: Royal Pharmaceutical Society of Great Britain and Merck Sharp and Dohme; 1996.

41. Horne R, Weinman J, Barber N, Elliot R, Morgan M. Adherence and Compliance in Medicine Taking. Report for the National Coordinating Centre for NHS Service Delivery and Organization R and D (NCCSDO). Available from: http://www.sdo.lshtm.ac.uk/files/project/76-finalreport.pdf. Accessed April 11, 2013

42. van Dijk L, Heerdink ER, Somai D, et al. Patient risk profiles and practice variation in nonadherence to antidepressants, antihypertensives and oral hypoglycemics. BMC Health Serv Res. 2007;7:51.

43. Zedler BK, Kakad P, Colilla S, Murrelle L, Shah NR. Does packaging with a calendar feature improve adherence to self-administered medication for long-term use? A systematic review. Clin Ther. 2011; $33(1): 62-73$ 
44. Ericsson. Traffic and Market Report. On the Pulse of Network Society. Available from: http://www.ericsson.com/res/docs/2012/traffic_and_ market_report_june_2012.pdf. Accessed April 11, 2013.

45. Cocosila M, Archer N. A framework for mobile healthcare answers to chronically ill outpatient non-adherence. Inform Prim Care. 2005;13(2):145-152.

46. Vervloet M, van Dijk L, Santen-Reestman J, et al. SMS reminders improve adherence to oral medication in type 2 diabetes patients who are real time electronically monitored. Int J Med Inform. 2012;81(9): 594-604.

47. Rollnick S, Butler CC, Kinnersley P, Gregory J, Mash B. Motivational interviewing. BMJ. 2010;340:c1900.

48. Rubak S, Sandbaek A, Lauritzen T, Christensen B. Motivational interviewing: a systematic review and meta-analysis. Br J Gen Pract. 2005;55(513):305-312.
49. DiMatteo MR, Haskard-Zolnierek KB, Martin LR. Improving patient adherence: a three-factor model to guide practice. Health Psychol Rev. 2012;6(1):74-91.

50. Herborg H, Haugbolle LS, Sorensen L, Rossing C, Dam P. Developing a generic, individualised adherence programme for chronic medication users. Pharm Pract. 2008;6(3):148-157.

51. Adhien P, Van Dijk L, Vegter M, Westein M, Nijpels G, Hugtenburg JG. Interventie op maat bij therapie-ontrouwe diabetespatienten; kwalitatief onderzoek naar de uitvoerbaarheid van de interventie. Pharmaceutisch Weekblad. 2012;147(1):2-6. German.

52. Lustria ML, Cortese J, Noar SM, Glueckauf RL. Computer-tailored health interventions delivered over the web: review and analysis of key components. Patient Educ Couns. 2009;74(2):156-173.

\section{Publish your work in this journal}

Patient Preference and Adherence is an international, peer-reviewed, open access journal focusing on the growing importance of patient preference and adherence throughout the therapeutic continuum. Patient satisfaction, acceptability, quality of life, compliance, persistence and their role in developing new therapeutic modalities and compounds to optimize clinical outcomes for existing disease states are major areas of interest. This journal has been accepted for indexing on PubMed Central. The manuscript management system is completely online and includes a very quick and fair peer-review system. Visit http://www.dovepress.com/ testimonials.php to read real quotes from published authors. 